\title{
Nipónio, Moscóvio, Tenesso e Oganésson
}

\author{
Paulo Correia, Luís Miguel Costa \\ Direção-Geral da Tradução, Comissão Europeia \\ Paulo.Correia@ec.europa.eu \\ Luis-Miguel.Costa@ec.europa.eu
}

\begin{abstract}
Nihonium, moscovium, tennessine, oganesson - This paper presents some reflections on the most appropriate names in Portuguese for chemical elements 113, 115, 117 and 118. IUPAC Recommendations 2002 and 2016 on names and symbols of new elements are taken into account as well as the solutions in other modern romance languages registered in IATE, the terminology database of the language services of the European institutions.

A presentam-se algumas reflexões sobre as designações mais adequadas em português para os elementos químicos 113, 115, 117 e 118. São tidas em conta as recomendações IUPAC de 2002 e 2016 relativas aos nomes e símbolos de novos elementos, assim como as soluções registadas noutras línguas neolatinas na base terminológica IATE dos serviços linguísticos das instituições europeias.
\end{abstract}

Na sequência de relatórios do grupo de trabalho conjunto da União Internacional de Química Pura e Aplicada (IUPAC) e da União Internacional de Física Pura e Aplicada (IUPAP) dando como provada a descoberta dos quatro elementos que faltavam no sétimo período da tabela periódica, a IUPAC publicou uma notícia a 8 de junho de 2016 [1] em que foram divulgados, para escrutínio público, os nomes em língua inglesa propostos pelos respetivos descobridores:

- Nihonium (símbolo Nh), para o elemento 113 (provisoriamente: unúntrio, Uut),

- Moscovium (símbolo Mc), para o elemento 115 (provisoriamente: unumpêntio, Uup),

- Tennessine (símbolo Ts), para o elemento 117 (provisoriamente: ununséptio, Uus) e

- Oganesson (símbolo Og), para o elemento 118 (provisoriamente: ununóctio, Uuo).

Estas designações em inglês vieram a ser confirmadas pela IUPAC a 28 de novembro de 2016 [2].

A necessidade de fixar na base terminológica IATE [3] dos serviços linguísticos das instituições europeias as designações em português, e a correspondente ortografia, dos elementos químicos 113, 115, 117 e 118 levou a uma pesquisa de informação, que revelou a ocorrência de soluções por vezes discrepantes em língua portuguesa. Foram tidas em conta as recomendações de 2002 e 2016 da IUPAC relativas aos nomes e símbolos de novos elementos [4,5], assim como as soluções entretanto registadas na base IATE noutras línguas neolatinas.

Com estes quatro novos nomes homenageiam-se três regiões geográficas (Japão, Moscóvia e Tenessi) e um cientista (Iuri Oganessian). Tradicionalmente, os elementos químicos recebem nomes relacionados com: a) um conceito ou um personagem mitológico (incluindo um objeto astronómico); b) um mineral, ou substância semelhante; c) um local ou uma região geográfica; d) uma propriedade do elemento; e) um cientista. Quanto aos sufixos escolhidos, foram três diferentes, indicativos das posições em grupos específicos da tabela periódica. As recomendações
IUPAC de 2002 indicavam que, por questões de coerência linguística, os nomes de todos os novos elementos deveriam terminar em «-io» («-ium» em inglês). Porém, as recomendações da IUPAC de 2016 retificaram este ponto, recomendando-se agora que os novos elementos acabem em «-io» («-ium» em inglês) para os elementos dos grupos 1 a 16, «-o» («-ine» em inglês) para os elementos do grupo 17 (halogénios) e «-on» («-on» também em inglês) para os elementos do grupo 18 (gases nobres).

Apresentam-se em seguida, para cada novo elemento, a tradução de excertos da referida notícia da IUPAC de 8 de junho e reflexões sobre as designações mais adequadas em português.

\section{Elemento 113 - homenagem ao País do Sol Nas- cente}

O nome [nihonium, em inglês] é proposto para associação direta com o país onde o elemento foi descoberto [o Japão]. O elemento 113 é o primeiro a ser descoberto num país asiático. A proposta apresentada pela equipa liderada pelo professor Kosuke Morita visa homenagear o trabalho pioneiro de Masataka Ogawa em 1908, associado à descoberta do elemento 43. A equipa espera igualmente que o orgulho e a esperança na ciência se possam sobrepor à descrença das vítimas da catástrofe nuclear de Fucoxima em 2011.

O País do Sol Nascente pode ser designado, quer pelo exónimo Japão quer por Nipão ou a sua variante Nião, adaptações para o português do endónimo 日本, transcrito no silabário hiragana e no alfabeto romaji como にっぽ ん/Nippon ou にほん/Nihon. O nome japonês Nippon é o mais usado para a maioria dos fins oficiais e está na origem de palavras como nipónico, niponismo, etc.

Em português, a opção por nipónio [6,7] para o elemento 113 tem a vantagem de indicar claramente que se quer homenagear o Japão. Convém, porém, ter em conta que, em 1908, Masataka Ogawa havia já proposto o nome nipónio (e o símbolo químico Np) para o elemento 43, que julgava ter então descoberto, e o qual foi mais tarde designado por tecnécio. Na realidade, terá encontrado o elemen- 
to que mais tarde foi designado por rénio (elemento 75). O símbolo Np foi reutilizado para o neptúnio (elemento 93), descoberto em 1940. No entanto, o nome nipponio (na grafia portuguesa da época) não foi encontrado na Internet (Google Livros) nem na consulta de fontes portuguesas coevas, como vocabulários, dicionários ou a Revista de Chimica Pura e Applicada [8]. A utilização de nipónio para o elemento 113 não colocará, assim, problemas de confusão com o elemento 43 nas obras em língua portuguesa.

De facto, as recomendações da IUPAC de 2002 e 2016 desaconselham que um nome que já tenha sido utilizado, mesmo de forma não oficial, seja reutilizado para outro elemento, de forma a evitar possíveis confusões na identificação dos elementos. Por este motivo, em inglês, foi avançada a proposta da designação nihonium, em detrimento de nipponium. Em inglês, há, efetivamente, registos anteriores de nipponium para o elemento 43, embora em número diminuto, como se pode comprovar no Ngram Viewer da Google [9].

Se em português se rejeitasse nipónio, a opção seria niónio [10], embora com o risco (que se passará com a maioria das outras línguas) de se perder o sentido imediato da homenagem ao Japão. No Brasil, a opção por niónio, ou melhor, por niônio, levantaria a questão adicional da possível confusão com o (quase) homófono neônio (néon). Niónio poderá confundir-se também com o catião neónio $\left(\mathrm{NeH}^{+}\right)$, resultante da protonação do gás nobre néon. A variante nihónio [11] será de rejeitar pela presença do «h» intervocálico, estranho ao português. Convém ter em conta que em português é mais comum a adaptação gráfica de topónimos do que a de antropónimos (veja-se bóhrio ou rutherfórdio). Se do topónimo Nippon/Nipão resulta nipónio (com um só «p»), de Nihon/Nião resultaria niónio (sem «h») e não nihónio.
A opção por japónio, claríssima na homenagem ao Japão, será também de rejeitar por não observar a desejada proximidade das designações nas diferentes línguas. Os descobridores do elemento optaram claramente por um endónimo, em detrimento do exónimo Japão.

Os nomes dos elementos dos grupos 1 a 16 do sétimo período da tabela periódica terminam todos com o sufixo «-io» («-ium» em inglês). É o caso do nipónio (grupo 13). Consultar o Quadro 1 para as designações noutras línguas neolatinas.

\section{Elemento 115 - homenagem à região de Moscovo}

Moscovium [em inglês] refere-se à região de Moscovo, homenageando a histórica região russa onde está situado o Laboratório Flerov de Reações Nucleares do Instituto Unificado de Investigação Nuclear [IUIN], de Dubna, local onde foram realizadas as experiências de descoberta, no separador de núcleos de recuo com câmara de gás [12] em combinação com o acelerador de iões pesados [13].

O nome moscóvio [14] homenageia a Moscóvia, região onde se situa Moscovo, terminando com o sufixo «-io», correspondente ao grupo 15 no sétimo período da tabela periódica. Consultar o Quadro 2 para as designações noutras línguas neolatinas.

\section{Elemento 117 - mais um halogénio}

Tennessine [em inglês] é proposto em reconhecimento pela contribuição da região do Tenessi, onde se situam o Laboratório Nacional de Oak Ridge (ORNL), a Universidade de Vanderbilt e a Universidade do Tenessi em Knoxville, na investigação no domínio dos elementos superpesados [transactinídeos], incluindo a produção e a separação química de materiais-alvo especiais constituídos por actinídeos, usados na síntese de elementos super-

Quadro 1 - Designação dos elementos do Grupo 13 (grupo do boro) nas línguas neolatinas. ${ }^{a}$

\begin{tabular}{|l|l|l|l|l|l|l|}
\hline & $2{ }^{\circ}$ período & $3{ }^{\circ}$ período & $4{ }^{\circ}$ período & $5{ }^{\circ}$ período & $6 .{ }^{\circ}$ período & $7 .{ }^{\circ}$ período \\
\hline símb. & $\mathbf{B}$ & Al & Ga & In & Tl & Nh \\
\hline pt & boro & alumínio & gálio & índio & tálio & nipónio \\
\hline fr & bore & aluminium & gallium & indium & thallium & nihonium \\
\hline es & boro & aluminio & galio & indio & talio & nihonio \\
\hline it & boro & alluminio & gallio & indio & tallio & nihonio \\
\hline ro & bor & aluminiu & galiu & indiu & taliu & nihoniu \\
\hline en & boron & aluminium & gallium & indium & thallium & nihonium \\
\hline
\end{tabular}

${ }^{\text {a }}$ Referência: IATE [3]

Quadro 2 - Designação dos elementos do Grupo 15 (grupo do nitrogénio) nas línguas neolatinas. ${ }^{\text {a }}$

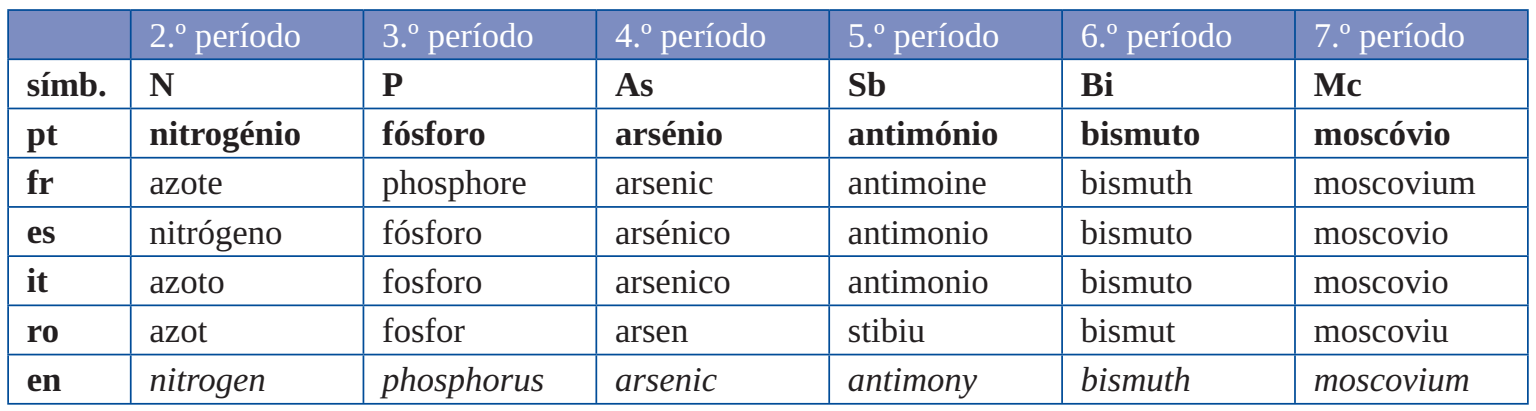

${ }^{a}$ Referência: IATE [3] 
pesados no Reator de Alto Fluxo para Produção de Isótopos (HFIR) e Centro de Desenvolvimento de Engenharia Radioquímica (REDC) do ORNL.

Repare-se que o nome escolhido em inglês foi tennessine e não tennessium. Assim, além de se homenagear a região norte-americana do Tenessi, com a escolha do sufixo inglês «-ine», quis-se indicar claramente que se está perante um halogénio.

Se se reparar nos pares flúor/fluorine, cloro/chlorine, bromo/bromine, iodo/iodine, ástato/astatine, a solução para o 117 deverá ser tenesso [15]. Soluções como tenessine, tenessina, tenessino ou tenessínio seriam decalques do inglês, enquanto tenéssio não indicaria que se trata de um halogénio. Seria o equivalente a utilizar, por exemplo, iodine, iodina, iodino, iodínio ou iôdio em vez de iodo.

Quanto a outras línguas neolatinas, a Société Chimique de France (SCF) [16] e a Real Sociedad Española de Química (RSEQ) [17] já se pronunciaram, utilizando as terminações habituais para os halogénios em francês («-e») e espanhol («-o»). Porém, consultando o Quadro 3, verifica-se que o italiano e o romeno parecem optar pela incorporação e adaptação do sufixo «-ine» inglês. De qualquer forma, não é ainda conhecida a posição da Società Chimica Italiana (SCI) [18] nem da Societatea de Chimie din România (SChR) [19].

\section{Elemento 118 - mais um gás nobre}

Para o elemento com o número atómico 118, as equipas de descobridores do Instituto Unificado de Investigação Nuclear, de Dubna (Rússia), e do Laboratório Nacional Lawrence Livermore (EUA) propuseram o nome oganesson [em inglês] e o símbolo Og. A proposta, em linha com a tradição de homenagear cientistas, reconhece o trabalho pioneiro do professor Iuri Oganessian (nascido em 1933) na investigação dos transactinídeos. Entre as suas muitas contribuições, contam-se a descoberta de elementos superpesados e avanços significativos na física nuclear dos núcleos superpesados, incluindo provas experimentais da «ilha de estabilidade».

Repare-se que o nome escolhido em inglês foi oganesson e não oganessium. É uma clara indicação de que se trata de mais um gás nobre e uma homenagem a Oganessian (Оганесян), cientista russo de ascendência arménia.

Com a exceção do hélio, a terminologia dos gases nobres é bastante clara nas várias línguas (sufixo «-on», correspondente à forma neutra de palavras do grego antigo). A designação em português será, assim, oganésson [20] (ou oganessônio, segundo a tradição da variante brasileira do português) e não oganessónio ou, muito menos, oganéssono ou oganéssão, como poderia resultar do aportuguesamento do termo inglês. A variante oganessão estaria em linha com radão (rádon), termo não normalizado ainda com bastante eco em Portugal [21], e a variante oganéssio não indicaria a posição no grupo 18 .

A IUPAC recomenda que os nomes dos elementos químicos difiram o mínimo possível entre as diferentes línguas (consultar o Quadro 4 para os nomes dos gases nobres noutras línguas neolatinas). Por maioria de razão, deverão, se possível, ser iguais nas variantes da mesma língua. É assim de registar a exceção interlinguística e intralinguística constituída pelos nomes dos gases nobres na variante brasileira do português - neônio, argônio, criptônio, xenônio, radônio. Essas designações podem ainda confundir-se com os nomes de catiões de gases nobres $-\mathrm{NeH}^{+}$: neónio (en: neonium), $\mathrm{ArH}^{+}$: argónio (en: argonium), $\mathrm{KrH}^{+}$: criptónio (en: kryptonium), $\mathrm{XeH}^{+}$: xenónio (en: xenonium), $\mathrm{RnH}^{+}$: radónio (en: radonium).

Quadro 3 - Designação dos elementos do Grupo 17 (halogénios) nas línguas neolatinas. ${ }^{\text {a }}$

\begin{tabular}{|l|l|l|l|l|l|l|}
\hline & $2 .^{\circ}$ período & $3 .^{\circ}$ período & $4 .^{\circ}$ período & $5 .^{\circ}$ período & $6 .^{\circ}$ período & $7 .^{\circ}$ período \\
\hline símb. & $\mathbf{F}$ & $\mathbf{C l}$ & $\mathbf{B r}$ & $\mathbf{I}$ & At & Ts \\
\hline pt & flúor & cloro & bromo & iodo & ástato & tenesso \\
\hline $\mathbf{f r}$ & fluor & chlore & brome & iode & astate & tenesse \\
\hline es & flúor & cloro & bromo & yodo & astato & tennesso \\
\hline it & fluoro & cloro & bromo & iodio & astato & tennessinio \\
\hline ro & fluor & clor & brom & iod & astatin & tennessin \\
\hline en & fluorine & chlorine & bromine & iodine & astatine & tennessine \\
\hline
\end{tabular}

${ }^{\text {a }}$ Referência: IATE [3]

Quadro 4 - Designação dos elementos do Grupo 18 (gases nobres) nas línguas neolatinas. ${ }^{\text {a }}$

\begin{tabular}{|l|l|l|l|l|l|l|l|}
\hline & $1{ }^{\circ}$ período & 2. $^{\circ}$ período & 3. ${ }^{\circ}$ período & 4. ${ }^{\circ}$ período & 5. ${ }^{\circ}$ período & 6. ${ }^{\circ}$ período & ${ }^{\circ}$ período \\
\hline símb. & He & Ne & Ar & $\mathbf{K r}$ & $\mathbf{X e}$ & Rn & Og \\
\hline pt (PT) & hélio & néon & árgon & crípton & xénon & rádon & oganésson \\
\hline pt (BR) & hélio & neônio & argônio & criptônio & xenônio & radônio & oganessônio \\
\hline fr & hélium & néon & argon & krypton & xénon & radon & oganesson \\
\hline es & helio & neón & argón & kriptón & xenón & radón & oganessón \\
\hline it & elio & neon & argon & kripton & xeno & radon & oganesson \\
\hline ro & heliu & neon & argon & kripton & xenon & radon & oganesson \\
\hline en & helium & neon & argon & krypton & xenon & radon & oganesson \\
\hline
\end{tabular}

${ }^{\mathrm{a}}$ Referência: IATE [3] 


\section{Referências}

[1] IUPAC, IUPAC is naming the four new elements nihonium, moscovium, tennessine, and oganesson, 08-06-2016, http:// iupac.org/iupac-is-naming-the-four-new-elements-nihonium-moscovium-tennessine-and-oganesson/ (acedido em 27-01-2017).

[2] IUPAC, Elements 113, 115, 117, and 118 are now formally named nihonium (Nh), moscovium (Mc), tennessine (Ts), and oganesson (Og), 30-11-2016, https:// iupac.org/iupac-announces-the-names-of-the-elements113-115-117-and-118/ (acedido em 27-01-2017).

[3] Inter-Active Terminology for Europe (IATE), http://iate.europa.eu/ (acedido em 27-01-2017).

[4] IUPAC, Naming of New Elements (IUPAC Recommendations 2002), https://www.iupac.org/publications/pac/2002/ pdf/7405x0787.pdf (acedido em 27-01-2017).

[5] IUPAC, Names and Symbols of the Elements with Atomic Numbers 113, 115, 117 and 118 (IUPAC Recommendations 2016), https://iupac.org/cms/wp-content/uploads/2016/11/ PAC-REC-16-05-01_preprint161128.pdf (acedido em 27-01-2017).

[6] Priberam, Dicionário Priberam da Língua Portuguesa, nipónio, https://www.priberam.pt/dlpo/nip\%C3\%B3nio (acedido em 27-01-2017).

[7] Porto Editora, Infopédia, nipónio, https://www.infopedia. pt/dicionarios/lingua-portuguesa/nip\%C3\%B3nio (acedido em 27-01-2017).

[8] Sociedade Portuguesa de Química, Rev. Chim. Pura App., http://www.spq.pt/magazines/rcpa (acedido em 27-01-2017).

[9] Google Books: Ngram Viewer, nipponium, rhenium, technetium,https://books.google.com/ngrams/graph?c ontent=nipponium\%2Crhenium\%2C+technetium\&ye ar_start $=1900 \&$ year_end $=2008 \&$ corpus $=15 \&$ smooth ing $=3 \&$ share $=\&$ direct_url=t1\%3B $\% 2$ Cnipponium $\% 3$ B\%2Cc0\%3B.t1\%3B\%2Crhenium\%3B\%2Cc0\%3B. t1\%3B\%2Ctechnetium\%3B\%2Cc0 (acedido em 27-01-2017).
[10] Priberam, Dicionário Priberam da Língua Portuguesa, niónio, https://www.priberam.pt/DLPO/ni\%C3\%B3nio (acedido em 27-01-2017).

[11] Priberam, Dicionário Priberam da Língua Portuguesa, nihónio, https://www.priberam.pt/DLPO/nih\%C3\%B3nio (acedido em 27-01-2017).

[12] Joint Institute for Nuclear Research: Flerov Laboratory of Nuclear Reactions, Gas-Filled Separator (GFRS), http:// flerovlab.jinr.ru/flnr/gns.html (acedido em 27-01-2017).

[13] Joint Institute for Nuclear Research. Flerov Laboratory of Nuclear Reactions, U400 Accelerator Complex, http:// flerovlab.jinr.ru/flnr/u400.html (acedido em 27-01-2017).

[14] Porto Editora, Infopédia, moscóvio, https://www.infopedia. pt/dicionarios/lingua-portuguesa/mosc\%C3\%B3vio (acedido em 27-01-2017).

[15] Porto Editora, Infopédia, tenesso, https://www.infopedia. $\mathrm{pt} /$ dicionarios/lingua-portuguesa/tenesso (acedido em 27-01-2017).

[16] Société Chimique de France, Nihonium, moscovium, tenessine et oganesson font leur entrée officielle dans le tableau périodique, http://www.societechimiquedefrance.fr/ Nihonium-moscovium-tenessine-et-organesson-font-leurentree-officielle-dans-le.html (acedido em 27-01-2017).

[17] Real Sociedad Española de Química, ¿Sabes los nombres en español de los últimos elementos químicos aceptados por la IUPAC?, http://rseq.org/blog/generales/item/1215\%C2\%BFsabes-los-nombres-en-espa\%C3\%B1ol-de-los\%C3\%BAltimos-elementos-qu\%C3\%ADmicos-aceptados-por-la-iupac (acedido em 27-01-2017).

[18] Società Chimica Italiana, https://www.soc.chim.it/ (acedido em 27-01-2017).

[19] Societatea de Chimie din România, http://www.schr.org.ro/ (acedido em 27-01-2017).

[20] Porto Editora, Infopédia, oganésson, https://www.infopedia.pt/dicionarios/lingua-portuguesa/ogan\%C3\%A9sson (acedido em 27-01-2017).

[21] DECO, Teor de radão, https://www.decomais.pt/casa/teorde-radao (acedido em 27-01-2017).

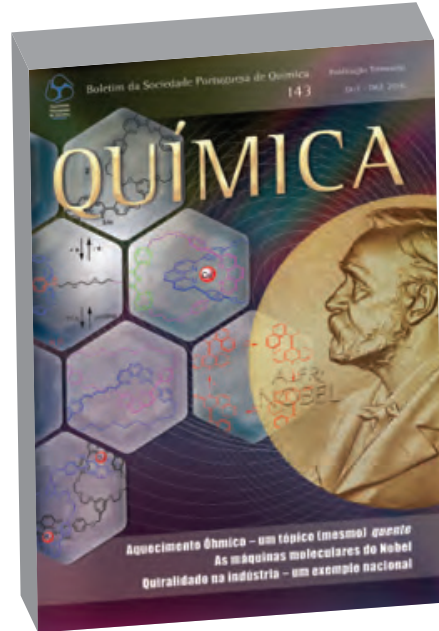

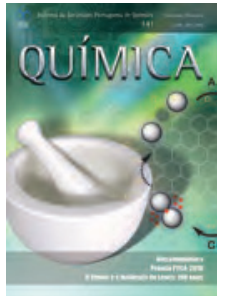

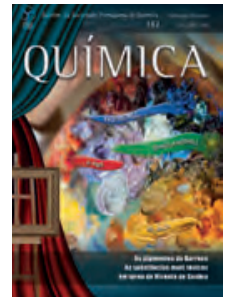

visite-nos em www.spq.pt

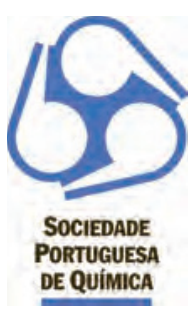

